\title{
EXPERIENCIAS CREATIVAS EN EL USO DEL MEDIO AUDIOVISUAL Y LAS TRAYECTORIAS DEL SUJETO*
}

\section{Marta Infante Jaras**}

\section{Resumen}

El propósito de este artículo es analizar cómo el uso de una metodología de autoexpresión estética audiovisual en talleres de cine posibilitaría la emergencia de subjetividades fluidas, en un contexto social donde los sujetos son excluidos a través de discursos estereotipados sobre discapacidad, inmigración y vulnerabilidad. En primer lugar, se proporcionan elementos de referencia teóricos que se relacionan con los conceptos de diferencia y medio audiovisual; luego, se describe el contexto donde se sitúa la implementación de talleres sobre cultura y realización audiovisual. A continuación, se introduce el diseño metodológico utilizado en los talleres y se presenta un caso a modo de ejemplo. Finalmente, se analizan los efectos de esta metodología en cuanto posibilidades que facilitarían procesos creativos en la construcción de subjetividades y se plantean algunos elementos de discusión.

Palabras clave: Autoexpresión estética, audiovisual, subjetividades.

\section{CREATIVE EXPERIENCES WITH THE AUDIOVISUAL AND THE TRAJECTORIES OF THE SUBJECT}

\begin{abstract}
The purpose of this article is to analyze how a methodology of aesthetic self-expression with audiovisual resources developed in specific workshops has allowed the emergence of fluid subjectivities within contexts where subjects are excluded by stereotypical discourses regarding disability, immigration, and vulnerability. First, a theoretical frame related to difference and audiovisual concepts is proposed; then, the article describes the context where audiovisual culture and production workshops are implemented. After that, both the workshops' methodological approach and a specific case of study are developed. Finally, the effects of this methodological approach in subjects' experiences are analyzed by revealing creative processes of subjectivities' construction and also, some elements for discussion are proposed.
\end{abstract}

Keywords: Aesthetic self-expression, audiovisual, subjectivities.

Recibido: 25-08-2016

Aceptado: 30-01-2017

* Este artículo se adscribe al Proyecto de Investigación Fondecyt Regular N¹130616: Propuesta de reflexividad audiovisual en escuelas públicas: una respuesta a la exclusión de subjetividades.

** Chilena. Ph.D. en Educación Especial de la University of Missouri-Columbia. Académica de la Facultad de Educación de la Pontificia Universidad Católica de Chile, Santiago, Chile. minfantj@ uc.cl 


\section{Introducción}

Este artículo se enmarca dentro de un proyecto Fondecyt Regular ( $\left.\mathrm{N}^{\circ} 1130616\right)$ que busca disminuir prácticas de exclusión en la escuela a través de una propuesta centrada en la auto-observación estética audiovisual y en el análisis crítico de las dinámicas de interacción. En particular, este artículo busca describir y analizar cómo una metodología que utiliza recursos audiovisuales de autoexpresión trabajada en talleres con estudiantes de séptimo año básico, favorece la emergencia de subjetividades fluidas y fragmentadas que se alejan de representaciones estereotipadas sobre lo que tiene que ser y aprender un estudiante de una escuela municipal chilena. Inicialmente, se presenta una introducción con conceptos significativos que permiten dar un marco de referencia al trabajo realizado en los talleres; luego, se describe el contexto específico donde se lleva a cabo la investigación. A continuación, se especifica el diseño metodológico elaborado para los talleres de audiovisual y se presenta un caso particular que permite ejemplificar su implementación. Finalmente, se analizan los resultados y se proporcionan algunos elementos conceptuales que contribuyen a la discusión.

En la actualidad se puede observar cómo el Estado de Chile ha desarrollado una serie de políticas públicas con el propósito de construir un sistema educacional que otorgue oportunidades de aprendizaje con equidad y calidad a todos nuestros estudiantes, poniendo énfasis en aquellos grupos de niños y jóvenes que eran excluidos del sistema a través de acciones y programas focalizados hacia la diferencia entendida como discapacidad, género, etnicidad, entre otros marcadores de identidad (ej. MINEDUC, 2007; MIDEPLAN, 2010; Gobierno de Chile, 2012). Sin embargo, esta aproximación a la diferencia no ha favorecido el desarrollo de nuevas subjetividades que se alejen de los estereotipos normativos pre-existentes (Grinberg, Infante, Matus y Vizcarra, 2014). En particular, las propuestas para abordarla han estado caracterizadas por una mirada reduccionista y desapegada de la formación de subjetividades que experimentan los sujetos (Infante, 2010). En otras palabras, los discursos relacionados con diferencia (ej. sexualidad, nacionalidad, discapacidad, entre otros) presentes en las políticas públicas chilenas, contemplan un ensamblaje pragmático de juicios de control y regulación de las corporalidades de los sujetos. Estos discursos implican tareas focalizadas y compensatorias para incluir a aquellos que 
se encuentran marginados de la educación y sociedad (Infante y Matus, 2009). Pero, estas aproximaciones discursivas sobre «inclusión de la diferencia» no contemplan una consideración y comprensión más amplia de las experiencias de los sujetos en la construcción de subjetividades, como por ejemplo, qué sucede cuando ellos y ellas sobrellevan efectos múltiples de discriminación por discapacidad, inmigración y/o nivel socio-económico (Matus e Infante, 2011).

Desde otra perspectiva, Hickey-Moody (2009) destaca cómo la construcción de subjetividades ha sido enmarcada socialmente bajo el binomio de capacidad/discapacidad. Al respecto, indica que la idea de falta de capacidad (discapacidad) se ha convertido en una forma de jerarquizar los cuerpos. Sin embargo, «[...] es una idea que describe una mente y no un cuerpo» (32). De esta forma, la autora destaca que si la mente puede ser vista como encarnada y articulada en percepciones sensoriales, emociones y memoria, el concepto de capacidad que es producto de esta idea, puede ser removido de lo material y lo sensorial. Es en esta representación del cuerpo donde el proceso de aprendizaje cobra relevancia como plano que posibilita la transformación de aquellos sujetos a esta imagen normativa de cuerpo discapacitado (Semetsky, 2006).

De acuerdo a Foucault (2002), el ordenamiento y control de los cuerpos descrito en el apartado anterior, son prácticas cotidianas presentes en instituciones modernas altamente estructuradas como las cárceles, los hospitales y las escuelas. Siguiendo a Deleuze y Guattari (1997), los sujetos están limitados en las trayectorias que realizan mediante propósitos preestablecidos y referencias cotidianas que les son disponibles en esos espacios (estriados). Así, la representación de lo que debe ser y hacer un sujeto está fijada por un presente puntual y determinista desde una perspectiva ontológica. Sin embargo, estos autores también indican la existencia de espacios (lisos) donde las trayectorias del sujeto no están delimitadas por recorridos ya designados, sino por el azar, el descubrimiento y la creatividad. Es en esta reflexión sobre el espacio donde se destaca la relación que establece Deleuze (2009) entre el cine y el pensamiento. La realización audiovisual posibilita el pensamiento con imágenes en reemplazo de los conceptos, estos últimos entendidos tradicionalmente como objetos pre-establecidos. Por su parte, la imagen es comprendida como proceso, transformación creativa y devenir. Más aún, la imagen-cine descrita por Deleuze alude a una relación 
rizomática entre lo visual y lo sonoro. Esto es, una conexión carente de subordinación, heterogénea y múltiple en cuanto a sus efectos constantes y transformadores. En otras palabras, el sujeto a través de su experiencia con el cine se abre a la visualización y producción de la vida cotidiana más allá de los marcos convencionales a los que está familiarizado, lo que le permite evadir sistemas rígidos de representación y control de la diferencia a través de movimientos nombrados como nomádicos según Deleuze, sin principio ni fin. Desde otra perspectiva, el trabajo con los medios audiovisuales se convierte en una potencia creativa cuando las imágenes del pasado son recogidas y actualizadas produciendo algo nuevo. Esa experiencia con la novedad, con lo desconocido a través de respuestas sensoriales es producida por el arte (Grosz, 2008).

La potencia creativa del aprendizaje mencionada por Deleuze (1994) es comprendida como una ruptura en la que un cuerpo se abre a fuerzas de diferencia y devenir. Así, siguiendo al autor, existiría aprendizaje cuando un cuerpo es transformado en sus capacidades de afectar y ser afectados por una serie infinita de experiencias. Al respecto, un autor que problematiza nociones tradicionales sobre los procesos de aprendizaje y enseñanza es Alain Bergala (2007). En particular, Bergala enfatiza que un trabajo explícito y sistemático de enseñanza en medios audiovisuales como instancia creativa posibilita la emergencia de cuerpos fluidos, múltiples e híbridos.

Durante las últimas décadas, ha habido un mayor interés por utilizar el lenguaje audiovisual como medio para indagar en prácticas culturales cotidianas (Pink, 2007) y como herramienta de expresión dinámica y creativa (Odendahl, 2003). El cine al tener la capacidad de capturar movimientos, sonidos y espacialidades, permite una práctica productiva en contextos sociales como el escolar. De acuerdo a Dussel (2009), las imágenes más que símbolos iconográficos, se transforman en acontecimientos que devienen efectos de una red discursiva que construye posiciones de sujeto. Más aún, Bergala (2007) indica que el cine permite interpelar prácticas excesivamente estructuradas en contenido, tiempo y espacio, al proporcionar desorden, desconcierto y conmoción. 


\section{El trabajo audiovisual: aproximaciones metodológicas}

La institución donde se realizan los talleres es un establecimiento educacional municipal perteneciente a la comuna de Santiago, Región Metropolitana. Se invitó a participar en el proyecto a esta institución debido a que los sujetos que la componen son «beneficiarios» de políticas estatales que abordan la diferencia: a) proyecto de integración y b) Ley de Subvención Escolar Preferencial (SEP). En particular, el establecimiento presenta un total de 465 sujetos matriculados en el año 2015, de los cuales, aproximadamente un 12\% son inmigrantes (nacidos primordialmente en Perú y Colombia) y un $6 \%$ participa en proyectos de integración escolar. Del mismo modo, un número importante de estos se encuentra en situación de riesgo social, evidenciado a través del índice de vulnerabilidad escolar (la escuela obtiene un índice de 58.3, dentro de un rango que va de 1 a 100, en mediciones realizadas por organismos estatales durante en el año 2015).

La investigación que enmarca este artículo considera la participación de 15 estudiantes que asisten a talleres voluntarios sobre cultura y realización audiovisual desde el año 2013 a la fecha. El grupo está compuesto aproximadamente de 6 niñas y 9 niños con una edad promedio de diez años al inicio de los talleres. Al respecto, es importante destacar que en los talleres no se indaga sobre las posibles representaciones estereotípicas del grupo, ya sea a través de una descripción particular de quiénes son esos sujetos desde documentos formales escolares o desde información proveniente de profesores, especialistas o directivos. Sin embargo, a partir de las primeras interacciones que se tienen con los estudiantes, emergen desde ellos declaraciones que hacen referencia a marcadores de subjetividades comúnmente estigmatizadas en el contexto escolar: vulnerables, peruanos, mapuches y discapacitados.

Los talleres tienen una duración de dos horas cronológicas y se realizan una vez a la semana (aproximadamente veinte sesiones anuales). Del mismo modo, se desarrollan fuera del horario regular de clases y en una sala facilitada por la escuela. En particular, el diseño y realización de los talleres está a cargo de una cineasta, un esteta, un ayudante y una educadora (investigadora responsable del proyecto Fondecyt). 
Durante el año 2015, los objetivos de los talleres se centraron en el desarrollo de relatos autobiográficos audiovisuales y en la integración de referencias autobiográficas (evidenciadas a través de un proceso de recogida de información de carácter etnográfico, realizado el primer año del proyecto Fondecyt) a otras formas de cultura y lenguaje audiovisual. En los talleres se utilizó como guía el trabajo de inserción de lo cinematográfico en la escuela a través del análisis de secuencias, promovido por Alain Bergala (2007). Específicamente, se buscó que los estudiantes identificaran diversos formatos dramáticos y distintas estructuras retóricas audiovisuales de expresión de la biografía y de la conciencia subjetiva. De manera consecutiva, se intencionó que los estudiantes desarrollaran habilidades relacionadas con la dimensión escrita de lo audiovisual, la narración de la experiencia (ej. secuencialidad dramática, serialidad causal, etc.) y con los géneros audiovisuales. Así, se realizaron variados ejercicios de narración audiovisual basados en experiencias autobiográficas de configuración de la identidad. Estos ejercicios incluyeron diversas etapas de producción del relato visual (ej. registro escrito de la idea, configuración de la secuencia dramática en tres etapas, elaboración de un guion técnico, estructuración del rodaje y su materialización) y su realización en soportes técnicos de complejidad creciente (ej. formato gráfico, audiovisual digital doméstico, etc.).

A partir de la estructura anteriormente descrita, los sujetos integrantes de los talleres, en una dinámica social alternativa al esquema jerárquico tradicionalmente utilizado en el aula, trabajaron a través de la mediación estética, motivada por el análisis colectivo de filmes y de libros álbumes, su conciencia cultural respecto de la diferencia y sus propias experiencias en la construcción de alteridad. Más aún, se propone una forma de visionado y reflexión de material audiovisual que Bergala (2007) describe como un análisis de creación donde no se busca un propósito específico, «... sino un pasaje hacia otra cosa» (127). A modo de síntesis, los talleres intentaron propiciar el avance en el conocimiento teórico, estético y técnico de la expresión audiovisual al servicio de la expresión de subjetividades. Del mismo modo, se fomentó el desarrollo de técnicas narrativas, literarias y audiovisuales de la expresión autobiográfica.

A continuación, se describirá un caso que ejemplifica el proceso metodológico realizado en los talleres y su respectivo desarrollo analítico. En particular, este muestra las derivaciones que tienen estas prácticas de autoexpresión estética audiovisual en la construcción de subjetividades. 


\section{Análisis de un caso}

De acuerdo a lo planteado en el apartado anterior, los talleres contemplaron ejercicios relacionados con la cultura y la realización audiovisual de manera de posibilitar la construcción de un espacio autobiográfico. A su vez, y de acuerdo a lo planteado por Arfuch (2002), un espacio con estas características busca conducir al reconocimiento de la presencia del otro y a la significación de la propia vida en esa interacción.

A partir del trabajo con visionados de films y ejercicios prácticos con técnicas audiovisuales, emergió el concepto de familia como un aspecto significativo tanto en la construcción del espacio autobiográfico de cada estudiante como en sus subjetividades. Debido a esto, se diseñó un trabajo que contemplaba la presentación de materiales audiovisuales (cortometraje, documental y extracto de película) relacionados con imágenes no-normativas de familia (ej. familia mono parental, situaciones de adopción, padres homosexuales, entre otras), el análisis reflexivo sobre sus propias experiencias de familia y la forma en que hoy se representa una familia en las escuelas y en el contexto mediático. Lo anterior permitió observar la expresión de una imagen naturalizada y hegemónica de la familia (ej. padre, madre, hijo) por parte de la mayoría de los estudiantes, produciendo interacciones complejas de exclusión en la sala. Por ejemplo, a pesar de que varios de los estudiantes manifiestaron pertenecer a familias monoparentales, dos estudiantes fueron enfáticos en plantear que una familia estaba compuesta por padre, madre e hijo, y cualquier cosa que se alejara de esa configuración (ej. imágenes representadas en los cortos expuestos), no era considerada una familia. Luego de estas reflexiones conjuntas, los estudiantes elaboraron guiones individuales (siguiendo una secuencia narrativa en tres escenas) sobre aquellos espacios de familia que ellos imaginaban y deseaban. De esta forma, se buscó que los estudiantes se abrieran a nuevas posibilidades de construcción de familia. Posteriormente, cada estudiante expuso oralmente su guion (ejercicio de pitching en lenguaje cinematográfico) al resto de los participantes con el propósito de escoger aquellos que serían filmados de acuerdo a sus preferencias. Lo anterior motivó a una reflexión colectiva donde los estudiantes debieron negociar el concepto de familia representado en las imágenes con aquel elaborado de su experiencia íntima para poder realizar una narrativa audiovisual ficcional y colectiva. 
Un caso interesante de analizar en este proceso reflexivo propiciado por los talleres fue el de Pablo, José y Juan, quienes a pesar de no evidenciar relaciones cercanas de amistad, decidieron trabajar juntos en el ejercicio de realización audiovisual. Al respecto, es importante destacar en este análisis de caso algunas particularidades del contexto educativo recogidas en el trabajo etnográfico realizado durante el primer año del proyecto global. Una de estas hace referencia a cómo estos estudiantes son objetos de representación de la otredad en los discursos presentes en la escuela (ej. discapacitados, inmigrantes y vulnerables), con efectos significativos de opresión en sus experiencias escolares. Durante el trabajo realizado en la escuela, se observa cómo Pablo, quien es nombrado en las narrativas de su profesor como discapacitado cognitivamente, participa de los talleres audiovisuales desde el primer año del proyecto y muestra un desarrollo importante de habilidades sociales, expresión (oral y escrita) y producción audiovisual. A través del ejercicio de imaginar un espacio familiar deseado, Pablo explicita que perdió a su padre hace dos años atrás y que su mayor anhelo es soñar con él. Debido a esto, elabora un guion que aborda esa experiencia y lo titula «El regreso» (de su padre). Por medio del ejercicio de pitching descrito con anterioridad, Pablo expone su trabajo a sus pares y la narrativa es escogida por dos compañeros, José y Juan, quienes expresan su deseo de participar en esa producción audiovisual.

En relación a los compañeros que seleccionaron el trabajo de Pablo, se observó que durante la reflexión colectiva sobre el guion y el concepto de familia, José y Juan reportaron tener una escasa relación con sus respectivos padres y coincidieron en hacer visible la ausencia de estos en la construcción biográfica del concepto de familia.

Los tres estudiantes comenzaron a trabajar con el registro narrativo de Pablo, interactuando, discutiendo y negociando las tres escenas principales del guion. Como resultado de este trabajo colaborativo, los estudiantes también incluyeron en la narrativa de Pablo algunas temáticas específicas que estaban relacionadas con sus propias experiencias autobiográficas. Por ejemplo, para José incorporar la práctica del skate en el guion era fundamental, puesto que, es una actividad que le permite abstraerse de los castigos por mal comportamiento que recibe regularmente en la escuela y en su casa. Por otro lado, a través de la 
recogida de información realizada en los talleres de años anteriores, se pudo visualizar que Juan es un estudiante nacido en Perú (situación que reporta como relevante en su experiencia de vida) y que se caracteriza por su capacidad para establecer excelentes interacciones sociales con sus compañeros en los talleres. Durante la sesión donde se aborda el concepto de familia, él manifiesta que su madre, hermano y compañeros de escuela son las personas más significativas en su vida. Del mismo modo, en la construcción del guion definitivo, manifiesta su interés por cumplir un rol de carácter colaborativo y secundario en la filmación (amigo del actor principal).

Es así como con posterioridad a la conformación de los grupos, estos estudiantes diseñaron el contenido final del audiovisual (guion) y escogieron los elementos y espacios necesarios para la producción del ejercicio, asumiendo procesos de dirección, actuación, arte y aspectos técnicos.

Es importante destacar que fueron los mismos sujetos quienes diseñaron y produjeron el cortometraje audiovisual de manera autónoma y que solamente recibieron apoyo cuando los tres aparecían actuando en escena. El audiovisual fue filmado en una sala de clases de la escuela y a continuación, se describen las tres escenas realizadas.

En particular, la primera escena muestra cómo Pablo duerme apoyado en una ventana, soñando (véase Figura 1).

Figura 1. Primera Escena

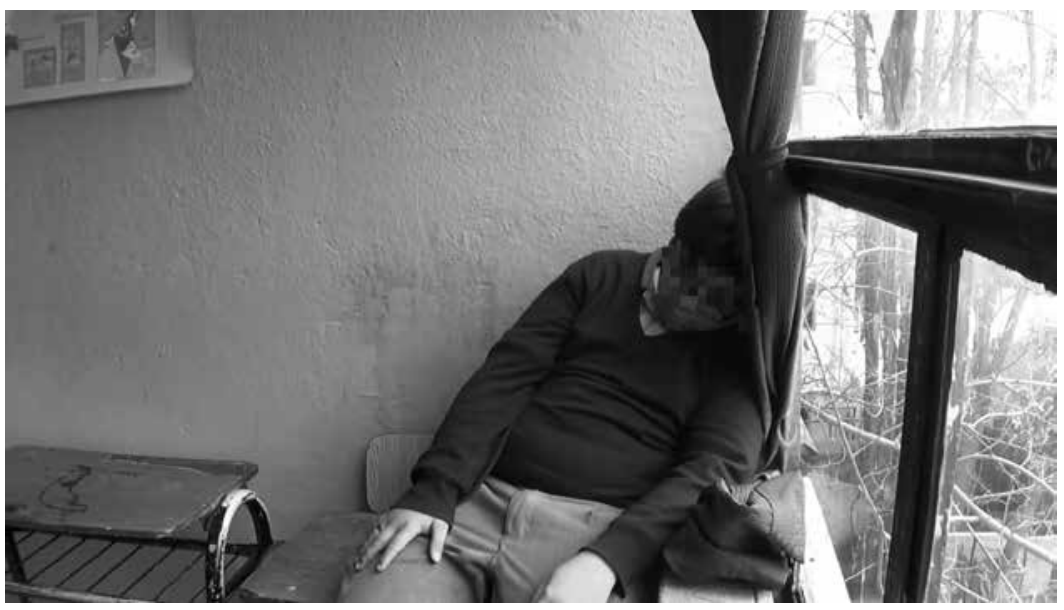


La segunda escena expone cómo José (padre de Pablo en el sueño) lo despierta y se ubica a su lado. Entra en escena Juan (amigo de Pablo en el sueño) y se observa cómo Pablo y él son invitados por el padre a andar en skate y recibir sus enseñanzas (véase Figura 2).

\section{Figura 2. Segunda Escena}

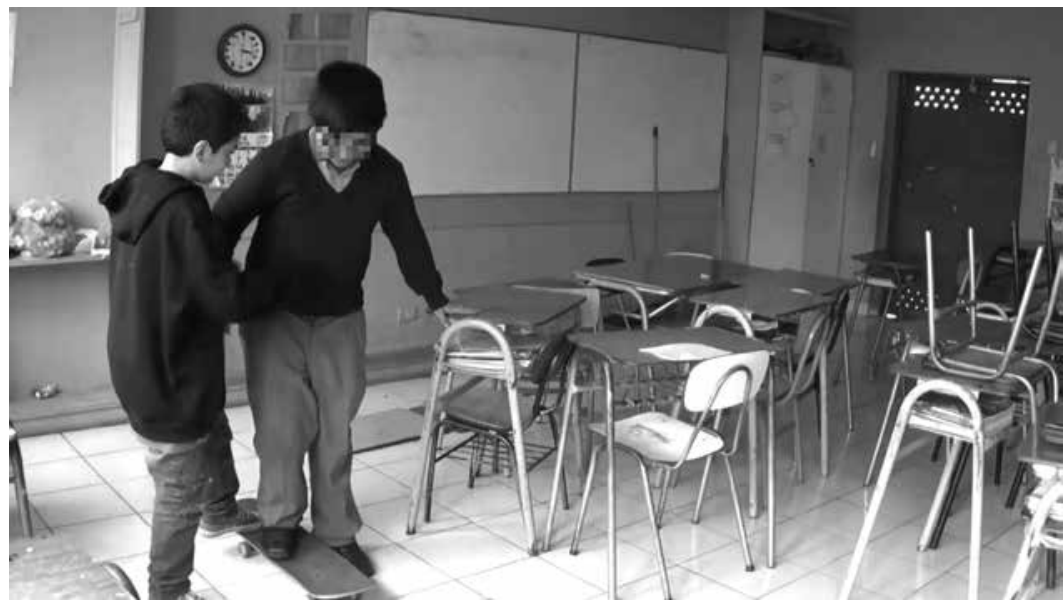

Finalmente, la tercera escena presenta a Pablo nuevamente dormido, apoyado en la ventana y Juan lo despierta (del sueño que estaba teniendo). Luego, Pablo le cuenta a Juan que acaba de soñar con su padre y que les enseñó a andar en skate a ambos. Finalmente, Pablo y Juan se muestran felices de haber compartido esa experiencia onírica (véase Figura 3).

Figura 3. Tercera Escena

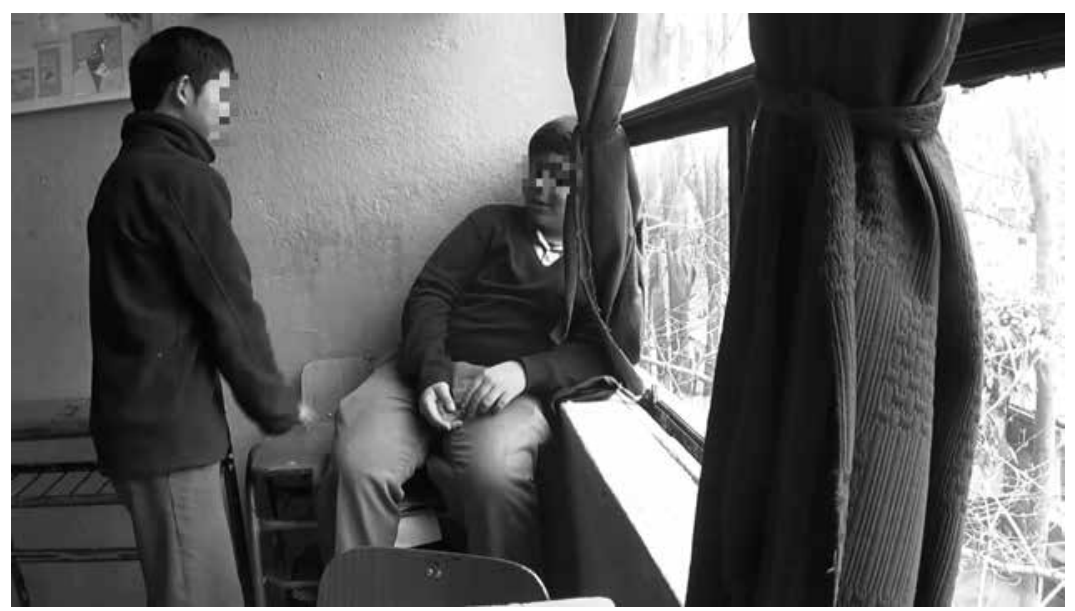


Es importante mencionar que después de la filmación del corto audiovisual, los tres estudiantes expresaron su felicidad y compartieron pensamientos y sensaciones sobre el ejercicio realizado. Al respecto, Pablo indicó: «Ahora puedo comprarme un skate, mi padre me enseñó como andar en skate»y añadió: «mañana puedo hacer cosas nuevas». Por su parte, Juan sonrió y junto con José manifestaron la entretención y alegría que les reportó la realización del ejercicio audiovisual.

El análisis del caso anterior permite profundizar en algunos aspectos interesantes que se pueden observar en el trabajo realizado en los talleres de cine. Un aspecto relevante alude a ilustrar cómo, por ejemplo, la reflexión estética sobre las imágenes no normativas de familia trabajadas en un contexto distinto al cotidiano (ej. talleres de cine) permitiría a los sujetos un diálogo colaborativo y autorregulado al manifestar representaciones normativas, ideales y deseadas. Más aún, en el proceso de creación de un audiovisual autobiográfico sobre sus familias, los sujetos transitaron nomádicamente entre posibilidades de habitar espacios familiares anteriormente no nombrados. De este modo, se observa cómo en lugar de abordar las representaciones de sí mismos y de sus propias familias como aproximaciones de estados ideales (normativos), el trabajo con audiovisual posibilitó las variaciones del yo. Pablo, José y Juan evidenciaron un alejamiento de los límites impuestos por los sistemas tradicionales de organización institucional (ej. estructura de la interacción y representaciones sociales de lo que debe ser una familia y ellos mismos).

Desde otra perspectiva, también se pudo observar cómo el trabajo de los niños permitió una relación explícita entre prácticas de análisis dramático y argumental de ficciones audiovisuales y sus propias experiencias afines. Los sujetos al compartir episodios autobiográficos y ajustarlos a procesos técnicos de elaboración narrativa y de producción audiovisual colectiva, modificaron la disposición del contexto social de los talleres y propiciaron una expresión íntima de episodios biográficos críticos. De esta forma, la disposición grupal para la reflexión, estimulada por habilitaciones audiovisuales, en el itinerario argumental de las propuestas narrativas autobiográficas, se movilizaron desde representaciones normativas del yo a formulaciones de relatos de reajuste biográficos con una naturaleza dramática onírica. Más aún, como plantea Arfuch (2013), las narrativas del yo «[...] se hacen más perceptibles en 
relación con la memoria en su intento de elaboración de experiencias pasadas y muy especialmente de experiencias traumáticas» (76). La expresión de las experiencias deseadas de los tres estudiantes mediante el lenguaje audiovisual logra una acción performativa al materializarse en un ejercicio fílmico que no solo enuncia una situación de duelo vivida, sino que la repara en términos comunicacionales.

En particular, los párrafos anteriores muestran un ejemplo de cómo un trabajo realizado por estudiantes a través de la creación de relatos autobiográficos (fílmicos) proporciona posibilidades para trabajar la subjetividad como material de creación y disposición frente al otro. El ejercicio seleccionado mediante el procedimiento de pitching de entre propuestas individuales de bases biográficas y realizadas mediante una distribución y organización colectiva de las tareas, beneficia la oportunidad estética de la expresión audiovisual como instancia de una construcción de subjetividades fluidas que se distancian de los estereotipos pre-establecidos en el contexto escolar. En este sentido, el proceso dramático motivador del relato (ausencia de los padres, familias deseadas, etc.) se expresa argumentalmente en un reajuste al concepto de familia, en un reencuentro onírico donde además, las propias subjetividades exceden más allá de las etiquetas con las que los estudiantes son interpelados (ej. discapacitado, peruano, entre otras). Esto último podría visualizarse a través del caso de Pablo, quien a pesar de la etiqueta que le ha sido asignada por la escuela (discapacidad cognitiva), se aleja de representaciones estáticas y esencialistas de su identidad pre-establecida socialmente. Más aún, el trabajo realizado por Pablo nos muestra cómo esta experiencia creativa va más allá del aprendizaje concreto del lenguaje audiovisual y se centra en su proyección, en lo que afecta y produce en los sujetos. La estructura tradicional de la familia y amigos es rota por el movimiento sugerido en las escenas filmadas. La expresión de los deseos y la posibilidad de creatividad invita a los sujetos a relacionarse con sus emociones, rechazar algunas y transformar otras. De acuerdo a Fresquet (2014) el trabajo con el cine permite alterar disposiciones de los cuerpos otorgadas a priori por los discursos institucionales y destruir las relaciones jerárquicas entre el sujeto capacitado y el discapacitado. El conocimiento, por tanto, transita fluidamente entre profesores y estudiantes a través del uso de medios técnicos sin temor a explorar formas de expresión audiovisual que permitan nuevas posibilidades en la construcción de subjetividades. 
El caso descrito a modo de ejemplo, de otras producciones desarrolladas en los talleres, muestra un movimiento rizomático de los estudiantes, cortando jerarquías y órdenes establecidos en la pedagogía tradicional que los definen como deficitarios. Los participantes de los talleres audiovisuales se convierten en sujetos que expresan una serie de itinerarios del yo que están en constante movimiento y que a su vez implican relaciones de poder y desplazamientos de significados sobre sus propias subjetividades.

\section{Conclusiones}

A partir de procesos de visibilización de sujetos que exceden la norma institucional, los discursos sobre diferencia en las escuelas chilenas se han focalizado en la codificación del cuerpo. Al respecto, Erevelles (2011) plantea que «[...] las posibilidades lingüísticas para los cuerpos discapacitados se inscriben a través de diferentes modos de codificación que incluyen ámbitos biológicos, políticos, económicos y culturales, entre otros, al mismo tiempo que permiten recodificaciones radicales [...]» (45). La inscripción de los cuerpos a una característica de identidad fija como discapacidad, nacionalidad y/o vulnerabilidad es una de las variadas posibilidades que podrían ser abiertas por medio de procesos estéticos de auto-expresión. En particular, la experiencia con los talleres de cultura y producción audiovisual permite observar cómo estudiantes que son posicionados en representaciones asignadas en el sistema educacional, muestran momentos en que se liberan de restricciones normativas para contemplar posibilidades en la construcción de subjetividades.

Desde otra perspectiva, y siguiendo a Deleuze y Guattari (1994), una persona no es una cosa en sí misma, sino que emerge de momento en momento (nomádicamente) desde ciertos movimientos entre imágenes o marcos. Su organización depende completamente de ciertas condiciones, en este caso motivadas por el trabajo sistemático, tematizado y creativo (uso de tópicos relativos a la construcción de la diferencia) con el lenguaje audiovisual.

Las experiencias de los sujetos denominados como discapacitados, inmigrantes o vulnerables en la escuela, no debieran ser reducidas a los estereotipos relacionados con su capacidad de aprendizaje, su país de origen o su nivel socio-económico, sino como posibilidades que permiten comprender cómo los sujetos se transforman en 'Otros' 
distintos de esas normas al establecer relaciones sociales, afectivas y de aprendizaje. En palabras de Braidotti (2009), los conceptos, cuerpos, y sus ejes de diferenciación (etnicidad, nacionalidad, etc.) aparecen de manera compleja y relacional, lo que a su vez produce mixturas infinitas. La creación de un espacio que utilice una aproximación al lenguaje (audiovisual) reflexiva y creativa, se convierte es una perspectiva metodológica que facilita no solo la comprensión de las experiencias opresivas que viven los estudiantes, sino que permite la reducción de representaciones fijas y simplistas sobre la formación de subjetividades en una institución tradicional como la escuela.

En síntesis, el uso de experiencias estéticas de auto-expresión audiovisual se presenta como una alternativa que facilitaría la construcción de los cuerpos y las posibilidades que tienen las subjetividades de moverse a través de espacios de devenir. Al respecto, Lohmann y Steyaert (2006) al citar el concepto de fabulación propuesto por Deleuze indican que «[...] mientras las historias son una forma a través de la que el pasado entra en el presente, las fabulaciones priorizan el futuro en el presente, expresando una multiplicidad virtual» (88). Así, la creación en el ensamblaje de lo visual con lo sonoro permite la emergencia de subjetividades heterogéneas al transitar espacios donde coexisten las imágenes del presente que mediante una relación de secuencias, actualizan el pasado. Específicamente, el uso de esta perspectiva metodológica no solo facilitaría a los sujetos cuestionar las situaciones opresivas a las que son expuestos, sino que les posibilitaría, a través de una capacidad creadora, ficcionalizar sus mundos y moverse nomádicamente alejándose de esas representaciones a las que son atados social, cultural y educacionalmente.

\section{Referencias bibliográficas}

Arfuch, L. Memoria y autobiografía. Exploraciones en los limites. Buenos Aires, Fondo de Cultura Económica, 2013.

_.. El espacio biográfico. Dilemas de la subjetividad contemporánea. Buenos Aires, Fondo de Cultura Económica, 2002.

Bergala, A. La hipótesis del cine, pequeño tratado sobre la transmisión del cine en la escuela y fuera de ella. Barcelona, Laertes, 2007. 
Braidotti, R. Transposiciones. Sobre la ética nómada. Barcelona, Gedisa, 2009.

Chile. Gobierno de Chile. Ley que establece medidas contra la discriminación. 2012, www.leychile.cl/Navegar?idNorma=1042092.

_. MIDEPLAN. Ley 20.422. Establece normas sobre igualdad de oportunidades e inclusión social de personas con discapacidad. 2010, www.leychile.cl / Navegar $/$ ?idNorma=1010903\&idVersion=201002-10\&idParte.

_. Ley General de Educación. 2009, www.leychile.cl/ Navegar?idNorma=1006043.

. MINEDUC. Programa de Educación Intercultural Bilingüe. 2007, www.mined uc.cl / biblio / documento / 200708240835400. ProgramadeEducaciO.

. Política Nacional de Educación Especial. 2005, portales.mineduc.cl/ usuarios / edu.especial / File/ DOCUMENTOS\%20VARIOS\%20 2008/ POLiTICAEDUCESP.pdf.

Deleuze, G. La imagen-tiempo. Buenos Aires, Paidós, 2009.

__. Difference and repetition. New York, Columbia University Press, 1994.

Deleuze, G. y Guattari, F. Mil Mesetas. Capitalismo y esquizofrenia. Valencia, Pre-Textos, 1997.

Dussel, I. Los nuevos alfabetismos en el siglo XXI. Desafíos para la escuela, conferencia en Virtualeduca. 2009, www.virtualeduca.info/ Documentos/veBA09\%20_confDussel.pdf.

Erevelles, N. Disability and difference in global contexts. New York, Palgrave Macmillan, 2011.

Foucault, M. Vigilar y castigar. Buenos Aires, Argentina, Siglo XXI Editores, 2002.

Fresquet, A. Cine y educación: la potencia del gesto creativo. Santiago de Chile, Ocholibros Editores, 2014.

Grinberg, S., Infante, M., Matus, C. y Vizcarra, R. «Espacios y subjetividades: Narrando las trayectorias de la vulnerabilidad». Estudios Pedagógicos, no. 40, 2014, pp. 203-219. 
Grosz, E. Chaos, Territory, Art. Deleuze and the Framing of the Earth. New York, Columbia University Press, 2008.

Hickey-Moody, A. Unimaginable Bodies: Intellectual Disability, Performance and Becomings. Rotterdam, Sense Publishers, 2009.

Infante, M. «Desafíos a la formación docente: Inclusión Educativa». Estudios Pedagógicos, no. 36, 2010, pp. 287-297.

Infante, M. y Matus, C. «Policies and practices of diversity: reimagining possibilities for new discourses». Disability $\mathcal{E}$ Society, no. 24, 2009, pp. 437-445.

Lohmann, P. \& Steyaert, C. «In the mean time: Vitalism, affects and metamorphosis in organizational change». Deleuze and the social. Eds. M. Fuglsang and B. Meier. Edinburgh, Great Britain: Edinburgh University Press, 2006, pp. 77-95.

Matus, C. \& Infante, M. «Undoing diversity: knowledge and neoliberal discourses in colleges of education». Discourse: Studies in the Cultural Politics of Education, no. 32, 2011, pp. 293-307.

Odendahl, J. «Embodied views to the visual through interdisciplinary and reflexive methodologies». Text and Performance Quarterly, no. 23, 2003, pp. 87-104.

Pink, S. Doing Visual Ethnography. London, Sage Publications, 2007.

Semetsky, I. Deleuze, Education and Becoming. Rotterdam, Sense Publishers, 2006.

Skliar, C. y Larrosa, J. Experiencia y alteridad en educación. Argentina, Bs. Aires, Homo Sapiens, 2009.

Slee, R. The irregular school: Exclusion, schooling and inclusive education. Madison NY, Routledge, 2011. 